\title{
Measurement of Heart Rate and Body Temperature Based on Android Platform
}

\author{
Musyahadah Arum Pertiwi ${ }^{\sharp 1,}$, I Dewa Gede Hari Wisana ${ }^{1}$, Triwiyanto $^{1}$, Sasivimon Sukaphat ${ }^{2}$ \\ ${ }^{1}$ Department of Electromedical Engineering PoltekkesKemenkes, Surabaya \\ Jl. Pucang Jajar Timur No. 10, Surabaya, 60245, Indonesia \\ ${ }^{2}$ Department of Mathematics, Faculty of Science Srinakharinwirot University Bangkok, Thailand \\ \#musyahadaharump@gmail.com, hariwisana88@gmail.com, triwiyanto123@gmail.com, sasivimon@g.swu.ac.th
}

\begin{abstract}
Article Info
Abstract

Article History:

Received June 9, 2019

Revised July 20, 2020

Accepted Jan 11, 2020

Heart rate and body temperature can be used to determine the vital signs of humans. Heart rate and body temperature are two important parameters used by paramedics to determine the physical health condition and mental condition of a person. Because if your heart rate or body temperature is not normal then you need to make further efforts to avoid things that are not desirable. The purpose of this study is to design a heart rate and body temperature. In this study, the heart rate is detected using a finger sensor which placed on the finger. This sensor detects the heart rate pulses through infrared

\section{Keywords:}

Heart Rate

Finger Sensor

Body Temperature

DS18B20

Android
\end{abstract}

This work is an open-access article and licensed under a Creative Commons Attribution ShareAlike 4.0 International (CC BY-SA 4.0).

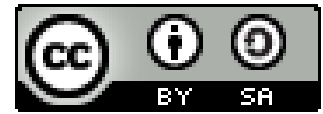

\section{INTRODUCTION}

Heart rate and body temperature are two important parameters that are used by paramedics to know the health condition of the physical and mental condition of a person. Because if the heart rate or body temperature is not normal it is necessary to further efforts in order to avoid things that are not desirable [1]. Heartbeat is a parameter to indicate the condition of one's heart, and one way to determine the condition of the heart is to know the frequency of the heartbeat. The normal human heart rate ranges from 60-100 beats per minute [2]. In addition to the heart, things that must be considered is the temperature of the body. The body temperature is very easy to change and change is influenced by many factors [3]. Factors changes in body temperature can indicate the condition of the body such as infection, inflammation, and stress [2]. Heart rate and body temperature are vital signs that are routinely checked at the hospital to determine the clinical signs and are useful to confirm the diagnosis of a disease. In the process, checks the heart rate and body temperature in some hospitals are still using manual systems where a nurse had to come to her room to watch and record heart rate and body temperature of the patient. This system is less effective because it takes a lot of time [4]. Both of these parameters can be used as well as early detection of clinical signs of sepsis or so-called systemic inflammatory response syndrome (SIRS). Sepsis is a systemic infectious disease that originated from the Systemic Inflammatory Response Syndrome (SIRS), SIRS shows the systemic response of the body against various trauma experienced by the body so that sepsis patients require special treatment to avoid organ damage [5]. The diagnosis of sepsis is made if found to be at least 2 clinical symptoms of Systemic Inflammation Response Syndrome (SIRS) such as body temperature $<36{ }^{\circ} \mathrm{C}$ or $>38{ }^{\circ} \mathrm{C}$, Speed pulse rate $>90$ beats / min, respiration rate $>20$ breaths / min or $\mathrm{PaCO} 2<32 \mathrm{mmHg}$, and blood white cell count $>12,000$ $/ \mathrm{mm} 3$ or $<4000 / \mathrm{mm} 3$ or $10 \%[6]$, Standard for the diagnosis of sepsis is the discovery of bacteria in the blood coupled with clinical symptoms of multiple organ disorders.

In $2015 \mathrm{~Sv}$ Viraktamath et al conducted a study entitled "Heartbeats And Temperature Monitoring Using ZigBee Protocol". The advantage of this study is the use zigbee protocol 
as the delivery of data from the microcontroller to the LCD, while the lack of this analysis, the temperature sensor is used still use the LM35 temperature sensor whose output is analog, not using a temperature sensor DS18B20 with accuracy higher than the LM35 [7]. The result output value is only displayed on the LCD $2 \times 16$ alone is not displayed on the android [8]. In 2016 Bandana Mallick and Ajit Kumar Patro conduct a study entitled "Heart Rate Monitoring System Using Finger Tip Through the Arduino and Processing Software". The advantage of this study is able to display signals ppg and BPM value on a computer, while the lack of this research that there is only one parameter, namely the parameters heart rate, body temperature parameter has not been found [9]. In 2017 Vikramsingh Parihar $\mathrm{R}$. et al conducted a study entitled "Heartbeat Monitoring System and Remote Patient Temperature for using Arduino". The advantages of this research is using NRF24L01 module for sending data from microcontroller which have a longer range than Bluetooth module $\mathrm{HC05}$, while the lack of this analysis, the temperature sensor is used still use the LM35 temperature sensor whose output is analog, not using a temperature sensor DS18B20 who have a higher accuracy than the LM35 [7]. The result output value is only displayed on the LCD 2 × 16 alone is not displayed on the android [10].

Based on the identification of the above problems, the purpose of this study is to design a tool measuring heart rate and temperature via to determine the value of heart rate and body temperature in patients and in case the value of belonging to a symptom early sepsis or systemic inflammation response syndrome (SIRS) called to serve as a reminder of the onset of the sepsis risk of disease.

\section{MATERIALS AND METHODS}

\section{A. Experimental Setup}

This research using adult subjects with criteria as respondents aged 15-65 years. Sampling is done randomly with data capture as much as 5 times.

\section{1) Materials and Tool}

This research use finger sensor Nellcor DS-100A to detect the BPM through the fingers and DS18B20 temperature sensor to detect the body temperature. The components used such as a microcontroller Atmega 328, op-amp as a filter and amplifier for signal processing BPM, LCD $2 \times 16$ and android as a display, and HC-05 Bluetooth module for sending data from the microcontroller to android.

\section{2) Experiment}

In this study measured the output of the filter circuit by using a function generator to provide input frequency and input amplitude, the output will be viewed on the oscilloscope. This measurement is intended to test the filter circuit is proven to work well in accordance with the filter characteristics or not. Researchers also perform measurements on DS18B20 sensor output to see how much the output amplitude by using an oscilloscope. Researchers conducted the BPM measurement of human body temperature of humans and randomized to the comparator Pulse Oximeter for BPM and a digital thermometer for comparison to body temperature.

\section{B. The Diagram Block}

In the part of the image that is given a dashed line is the parameter that the author made, namely the Heart Rate and Body Temperature parameters. The finger sensor detects the heartbeat signals on the finger and then processed by the filter circuit, the output filter circuit will be managed by ATmega328 into data Heart Rate. The temperature sensor will convert body temperature into digital data that is transmitted and managed by ATmega328 into data Body Temperature. Data Heart Rate and Temperature will be displayed on a $2 \times 16$ character LCD and transmitted using Bluetooth HC- 05 for display on android.

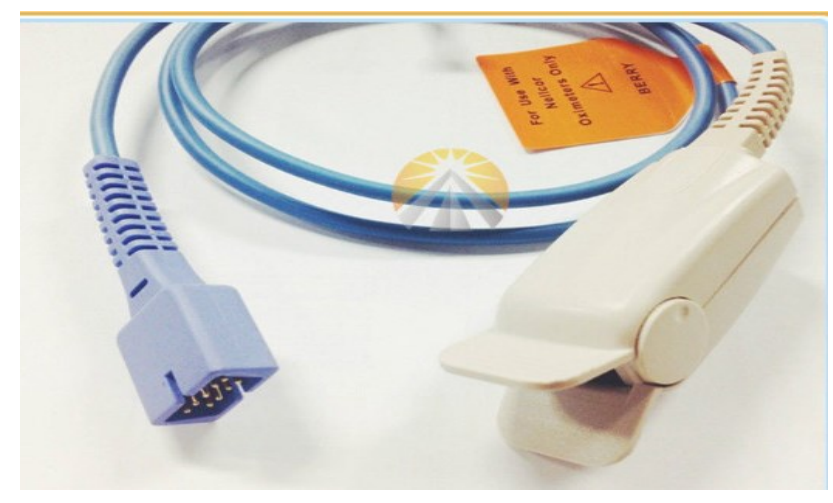

Fig. 1. Finger sensor

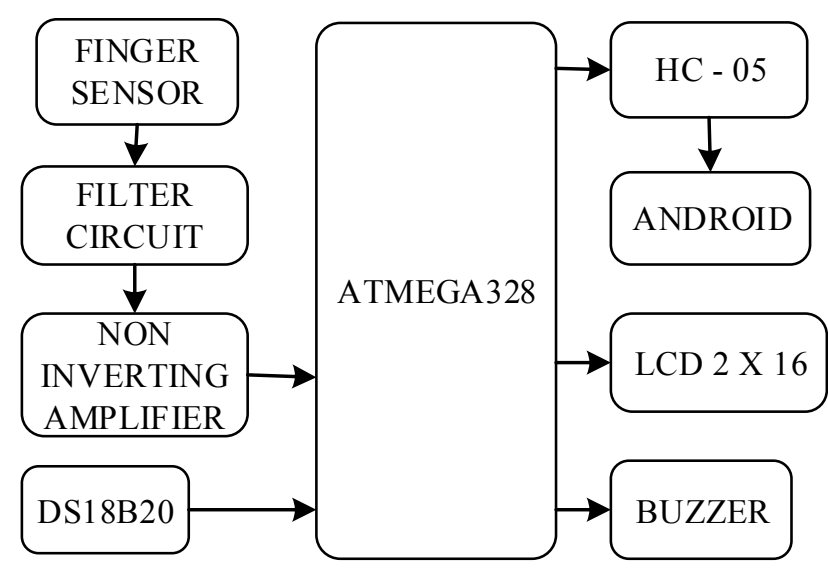

Fig. 2. The Diagram Blok 


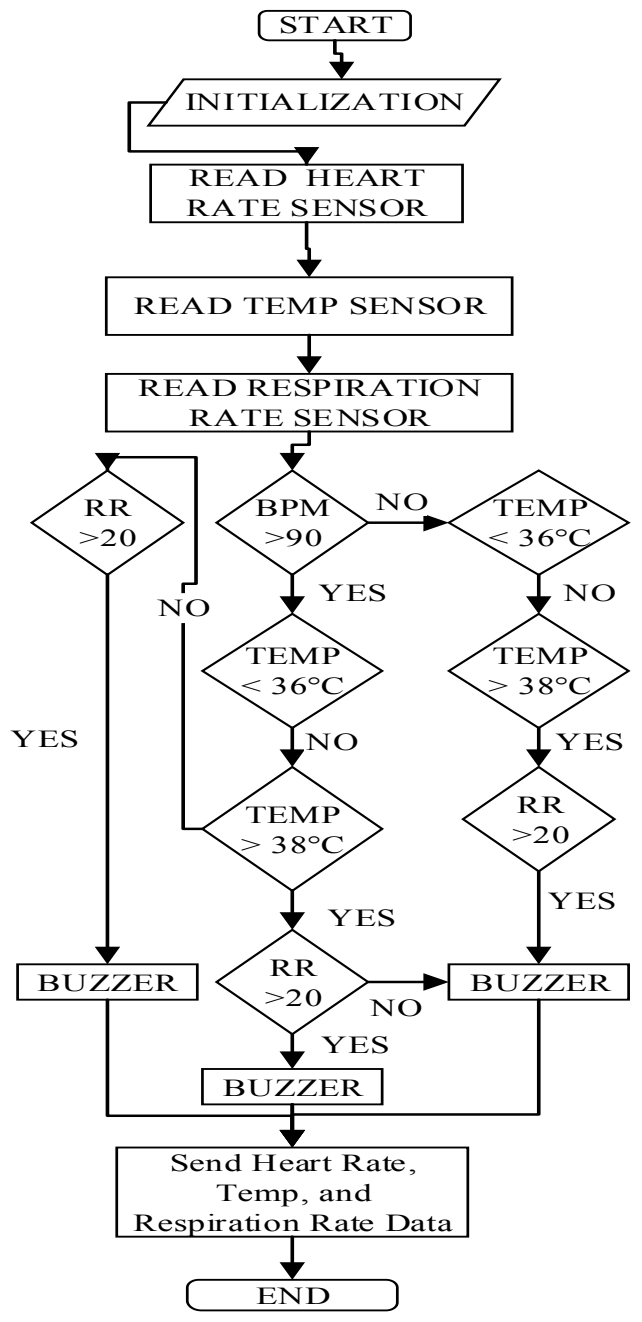

Fig. 3. The Flowchart of the Arduino Program

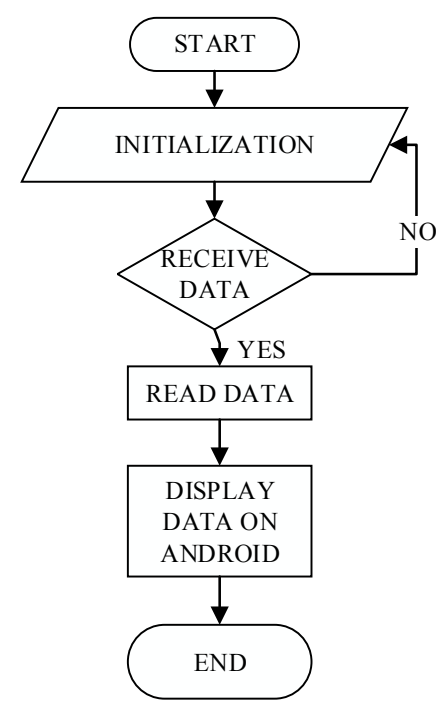

Fig. 4. The Flowchart of the Android

\section{The Flowchart}

Arduino program is based on a flowchart as shown in Fig. 2 and Fig. 3. After initialization, the sensor will start reading and processed on the ATmega328, then the result of processing is displayed on the LCD $2 \times 16$ and sent via Bluetooth in numbers to android. When the value of any two or all three of these three parameters show the value of the symptoms of sepsis or SIRS then the tool will beep buzzer to give a warning and the android screen will appear the words "Danger" as a form of warning.

\section{The Analog Circuit}

The important part of this tool is an analog circuit illustrated in Fig. 4 (Band Pass Filter). The circuit is used to process the heartbeat signal that has been read by the sensor.

1) Band Pass Filter

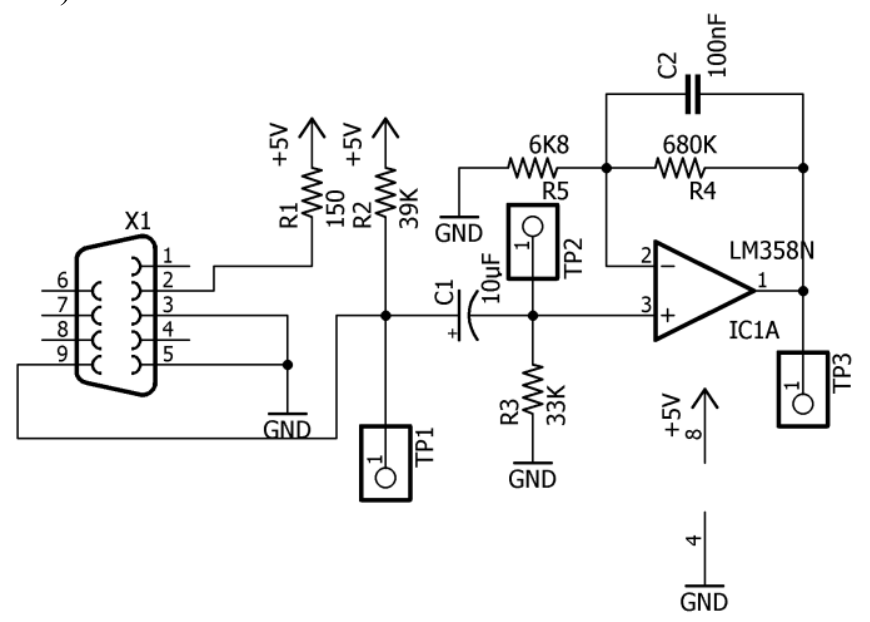

Fig. 5. Band pass filter

Band Pass Filter circuit shown in fig. 4 consists of a High Pass Filter and Low Pass Filter with Frequency Cut Off $0.5 \mathrm{~Hz}$ - 2.34 Hz. The output from the Band Pass Filter then reinforced by a non-inverting amplifier circuit of 101 times.

2) Temperature Sensor Circuit

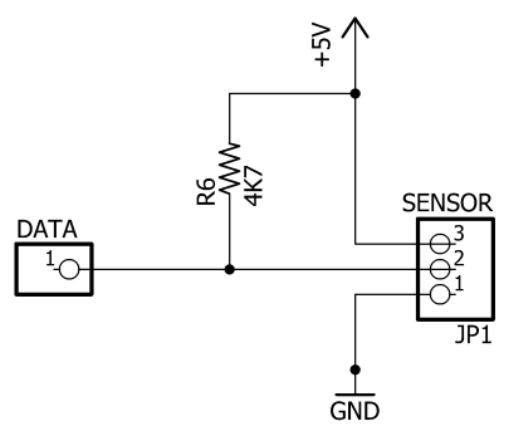

Fig. 6. Temperature Sensor Circuit

Series of temperature shown in Fig. 5 consists of a resistor in parallel pairs on the output of the sensor DS18B20. This resistor functions as a pull-up voltage of the output data generated by the sensors to be read up by Arduino. 


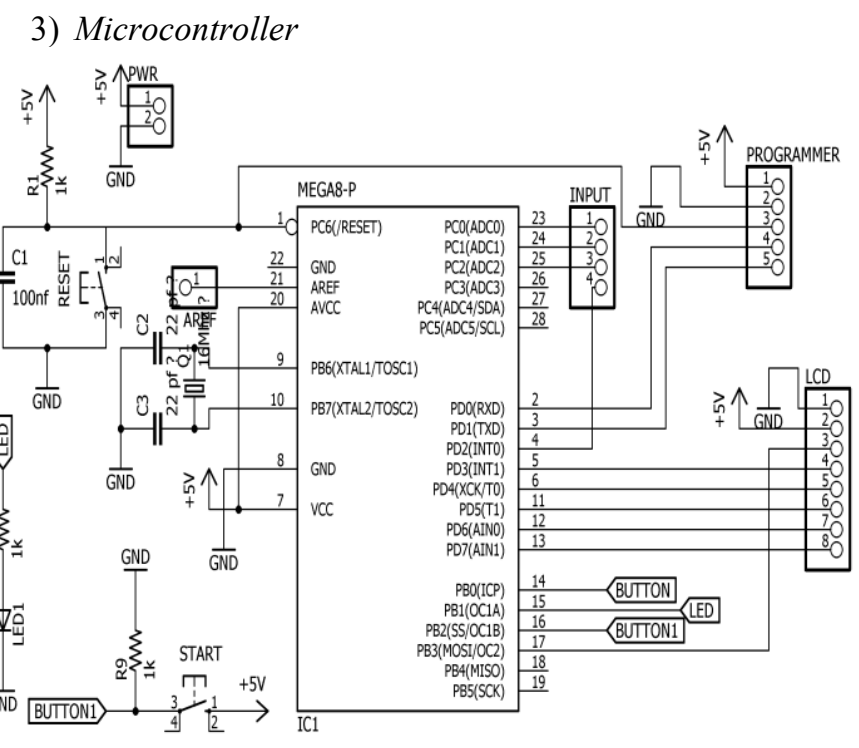

Fig. 7. Microcontroller

The microcontroller circuit is shown in fig. 6 used for processing the output data from each sensor. And is used for programming and data transmission with Bluetooth. The output of the filter circuit BPM will be connected to the analog pin A0 and temperature sensors connected to digital pin 2

\section{4) Bluetooth Module}

The Bluetooth module used in this tool is HC-05. The Bluetooth module is used to transmit data from the sensor readings to android. The Bluetooth module is connected to the microcontroller by connecting the microcontroller TX pin to the RX Bluetooth pin and vice versa, the microcontroller RX pin to the TX Bluetooth pin.

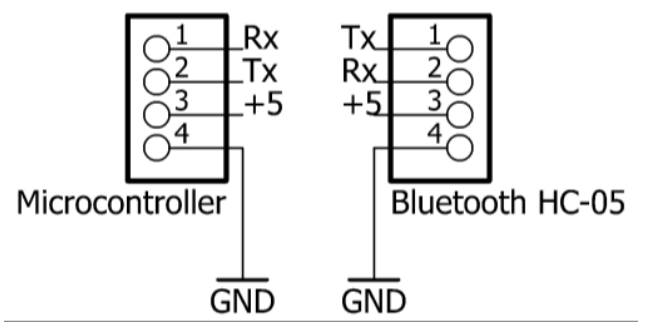

Fig. 8. Bluetooth Connection

\section{RESULTS}

This study has been carried out tests on the instrument directly on the human body are the fingers for BPM and axillary for temperature sensors. Researchers also perform measurements using pulse oxymeter (Elitech, FOX-1 (N)) and a digital thermometer (GP Care, Flexible Tip) as a comparison tool.

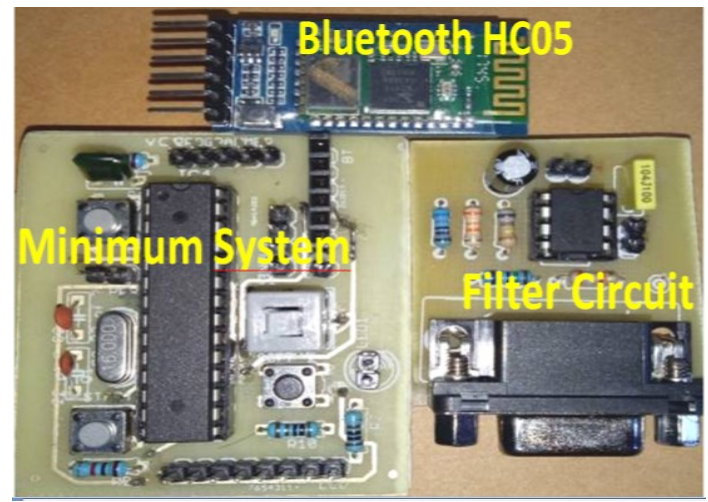

Fig. 9. Circuit Design

1) The Modul Design

The photograph of the analog and digital parts of the tool is shown in fig. 8. The analog section is a series of filters consisting of one LM358 (OP-AMP) which each unit consists of two OP-OMP. There are also several resistors and a capacitor. The digital part consists of a microcontroller which consists of ATmega328 as a regulator of the system, 16.000 $\mathrm{MHz}$ crystal that serves as an external clock for the functioning of the microcontroller. In the digital section, there is also an HC-05 Bluetooth module which is used to send data from the microcontroller to android.

\section{2) The Listing Program for Arduino}

Listing program Arduino consists of BPM value calculation program is shown in Listing 1 program, a program for displaying the value of the body temperature is shown in Listing program 2, program requirements early detection of the symptoms of sepsis are shown in Listing program 3, and programs to send data to the android program is shown in Listing program 4.

Listing program 1. BPM value calculation program

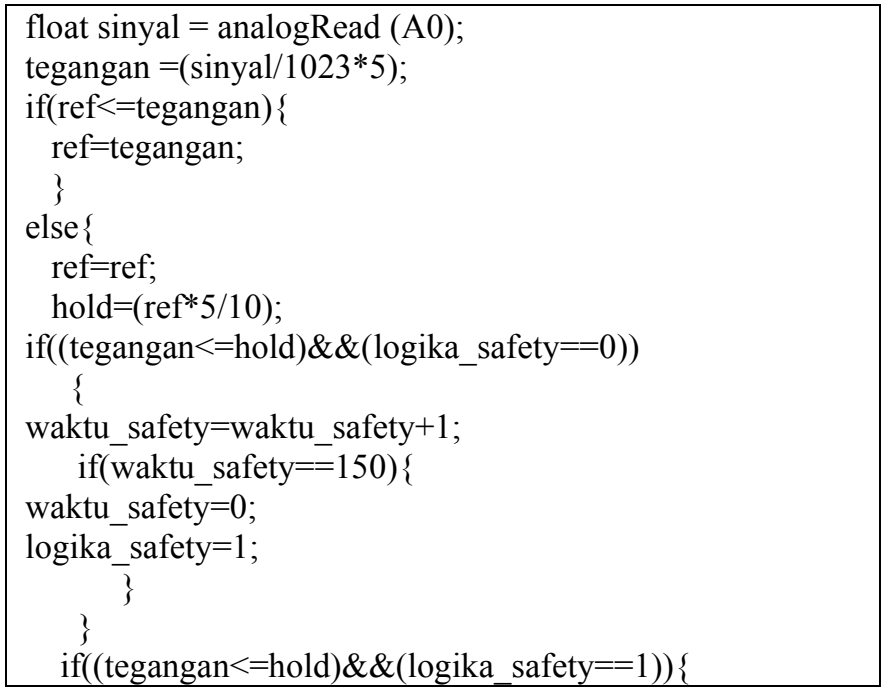




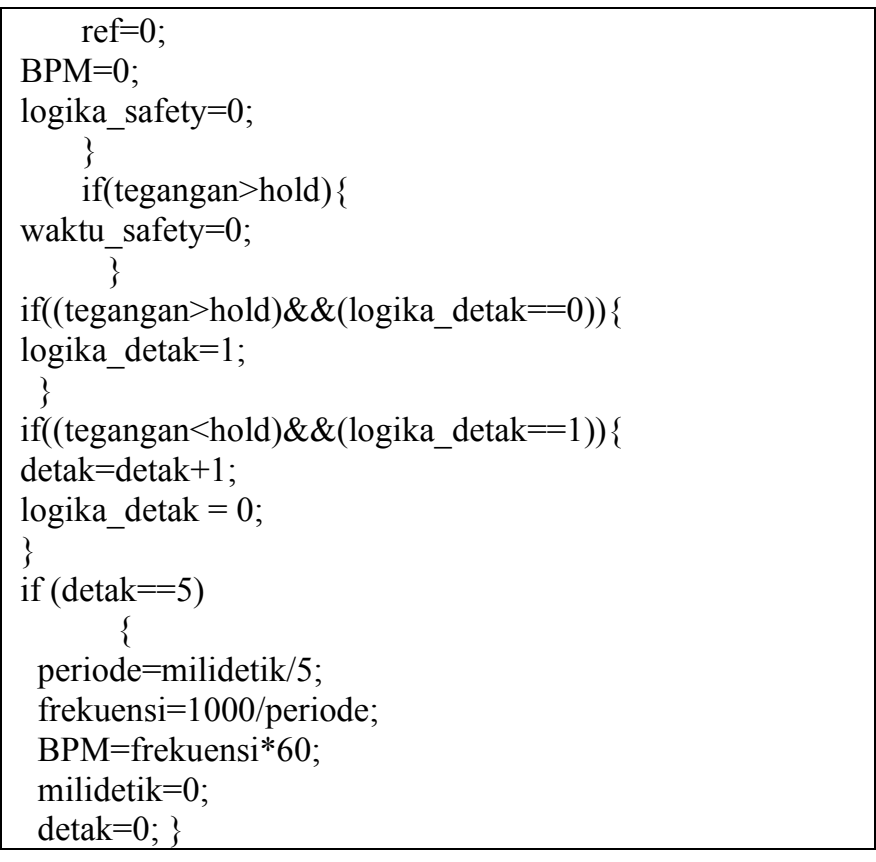

Listing Program 2. Program for displaying the value of the body temperature

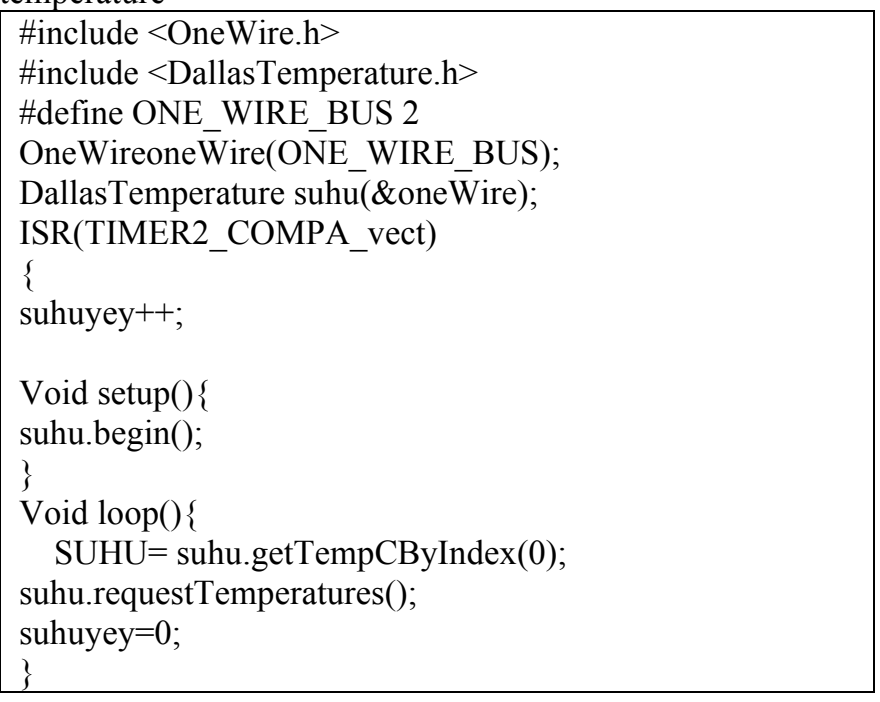

Listing Program 3. Program requirements early detection of symptoms of sepsis

\begin{tabular}{|} 
if $(36<\mathrm{SUHU}<38)\{$ \\
kondisisuhu $=1$ \\
\} \\
else \{ \\
kondisisuhu $=0$ \\
\} \\
if $(\mathrm{BPM}>90)\{$ \\
kondisiBPM $=1$ \\
$\quad$ else \{ \\
\hline
\end{tabular}

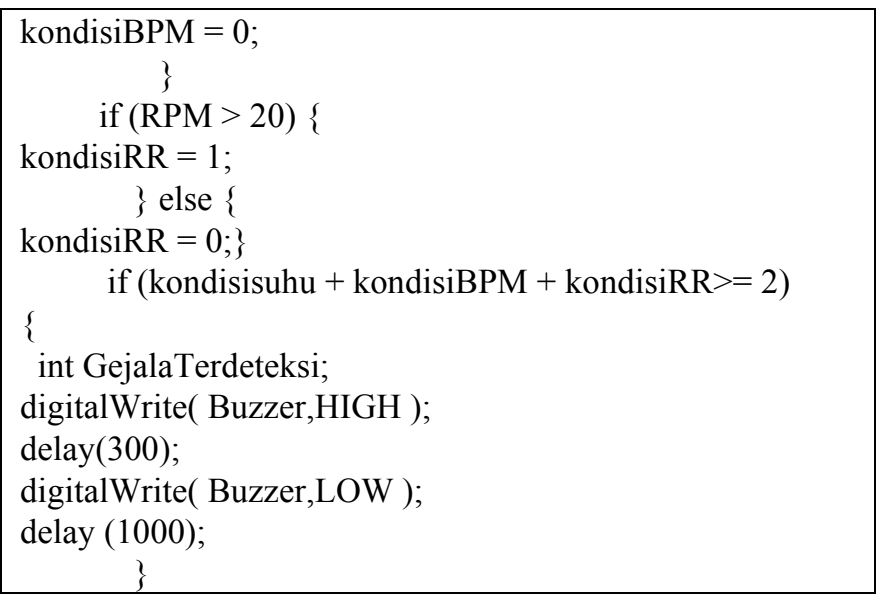

Listing Program 4. Program to send data to the android

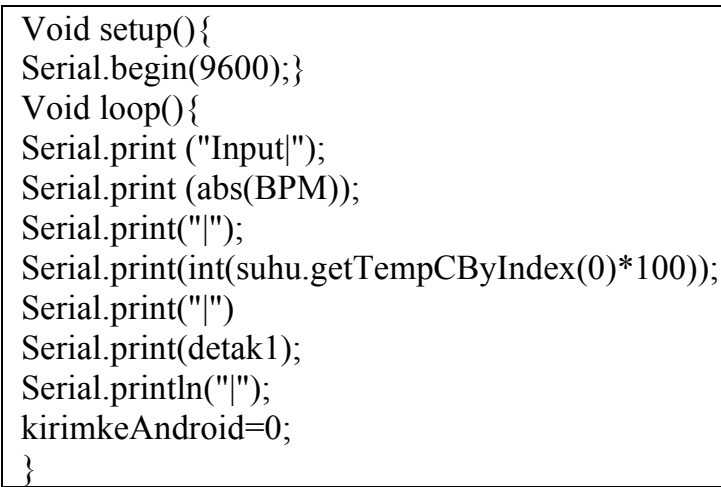

3) The Listing Program for Android Application

In this research to create android application using the Mit App Inventor. Programming to create android application consists of a program module connection bluetooth is shown in fig.9, the program received the data bpm is shown in fig.10, the program received the temperature data shown in fig.11, program requirements early detection of symptoms of sepsis shown in fig.12, the BPM graph plotting program shown in fig. 13, the temperature graph plotting program shown in fig.14.

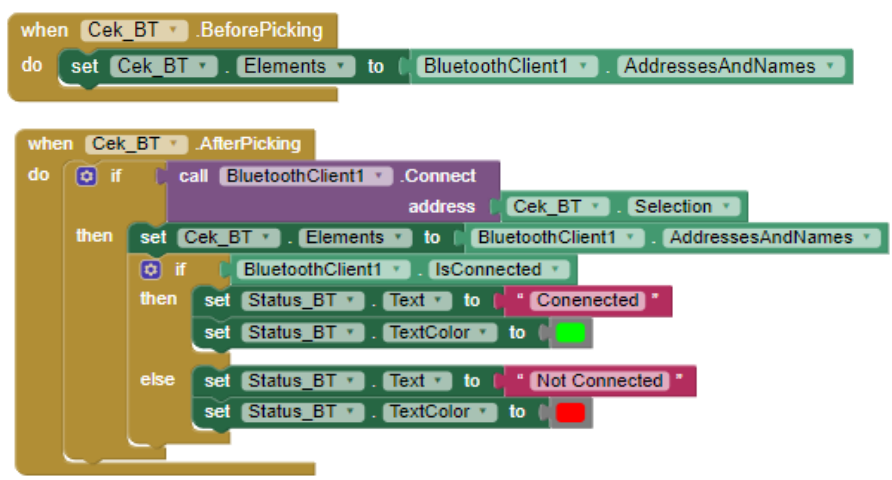

Fig. 10. Program Bluetooth module connection 
The block (Fig.9) is a program to open the list of names and addresses of Bluetooth will be selected as the data connection. Bluetooth on select should already be done a pairing with a mobile phone. The block also explains the status of the Bluetooth connection to android. After selecting the name and address of Bluetooth, the Bluetooth module will be connected with the android. When the Bluetooth module is connected with android applications, text that reads not connected will turn out to be connected and will change color from red to green. If the Bluetooth connection with the android application is lost then the text will re-read not connected and red.

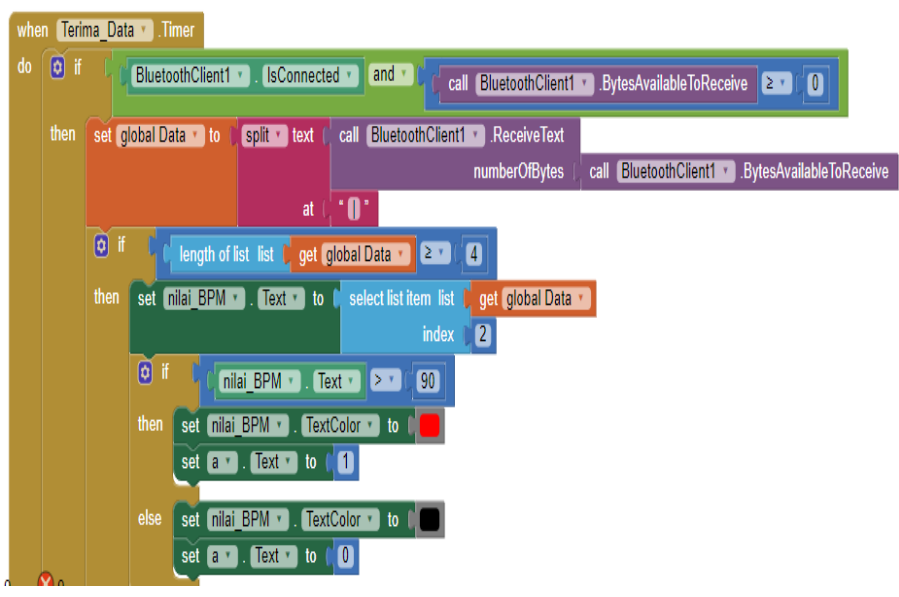

Fig. 11. Program received the data BPM

Pada In the block (fig.10) using the data split to separate the data received from the minimum serial communication system. When the time is running and if Bluetooth is connected and also the data received from the minimum system more than 0 , then the value of the list of global data into data results from the minimum system which has been separated with the character of a vertical line $(\mid)$, so that a list of such data in will automatically be sequential. Text in the BPM will contain data from the data on the global list of index 2 which means that the first list will be read as the value of BPM.

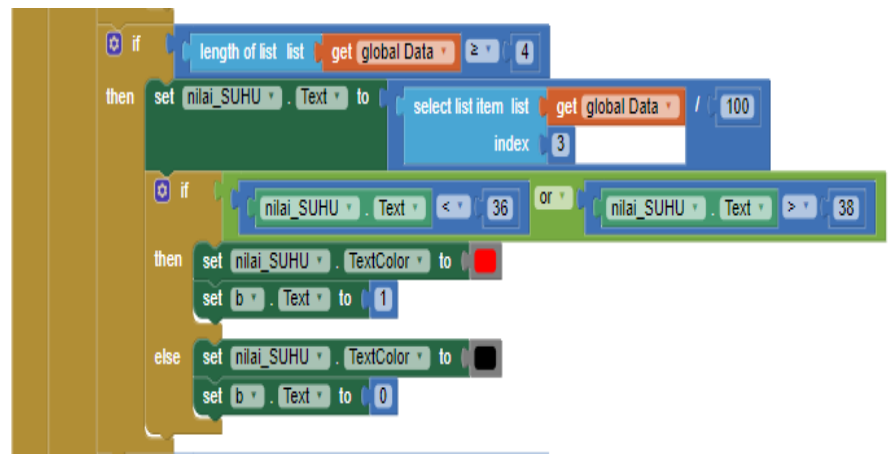

Fig. 12. Program received the data Temperature

In the block (fig.11), the text in temperature will contain data from the index data on the global list 3 which means that the second list will be read as a temperature value.

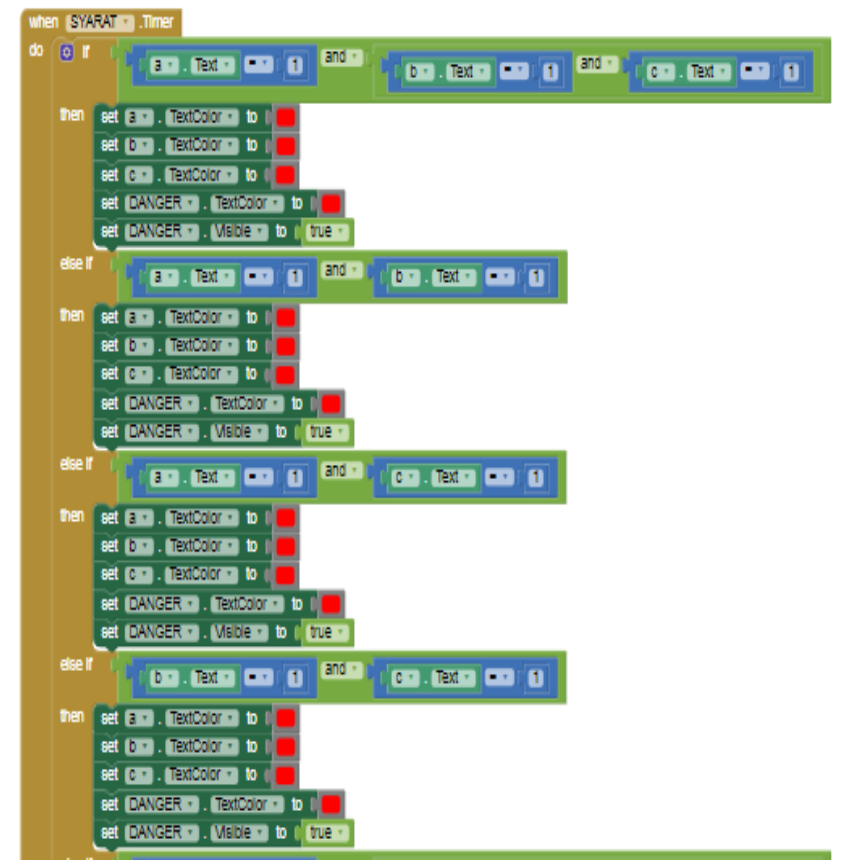

Fig. 13. Program requirements early detection of symptoms of sepsis

In the block (fig.12), consistent with the diagnosis of sepsis is made if found to be at least 2 clinical symptoms of Systemic Inflammation Response Syndrome (SIRS) such as body temperature $<36^{\circ} \mathrm{C}$ or $>38^{\circ} \mathrm{C}$, Speed pulse rate $>90$ beats $/ \mathrm{min}$, respiratory rate $>20$ breaths $/ \mathrm{min}$. Then every two out of three, or maybe a third of the clinical symptoms appear then the android application will display a warning in the form of text Danger of red and red color on text change parameter values from two or three parameters that show symptoms. Once these symptoms had not appeared then the value of the parameter text will turn black as before and text Danger will be lost.

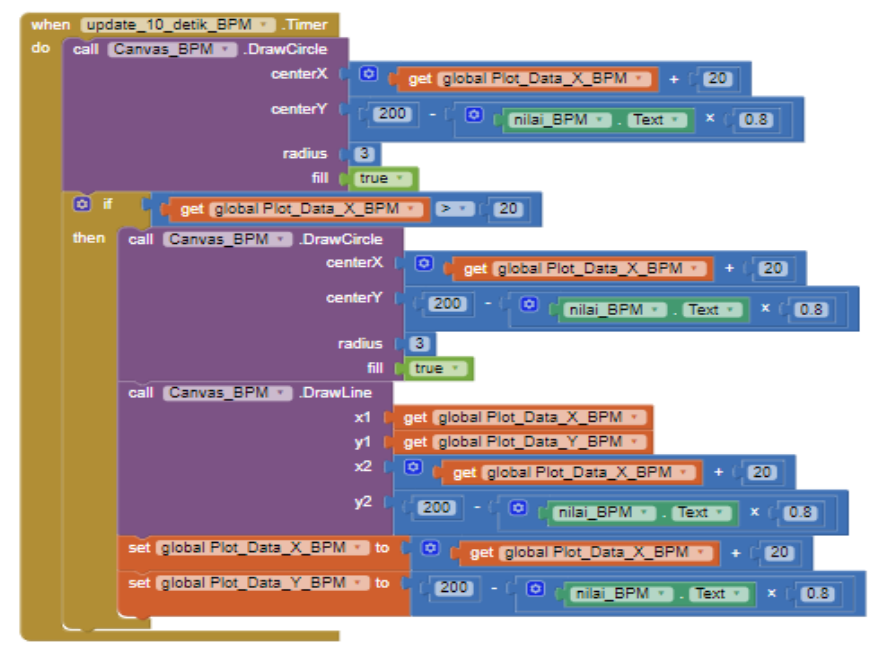

Fig. 14. BPM graph plotting program

The block (fig.13) is plotting the data from the BPM program. BPM itself in the data plotting using the plotting of 
points and lines so that the value of BPM which will form the graph appears in the form of lines and dots. Plotting is done once every 10 seconds for one minute so that the data in plotting amounted to 6 data. Y value obtained from the BPM value in the reading, to the value of $\mathrm{X}$ obtained from multiples of 10 seconds so that the data will form the pattern coordinates (X1, Y); (X2, Y); (X3, Y); (X4, Y); (X5, Y); (X6, Y);

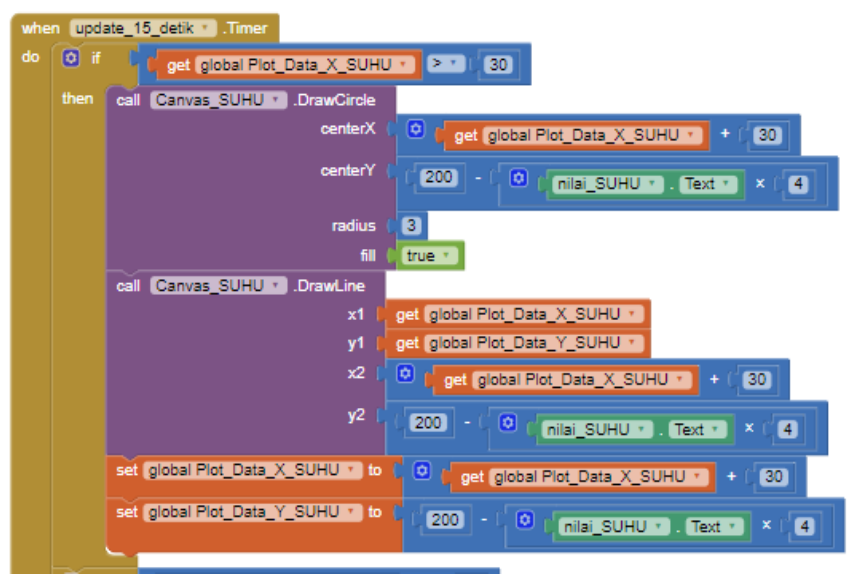

Fig. 15. temperature graph plotting program

In the blocks (fig.14) is a program of data plotting of temperature. Temperatures in the data plotting using the plotting of points and lines so that the temperature values that appear to form a graph in the form of lines and dots. Plotting is done once every 15 seconds for one minute so that the data in plotting amounted to 4 data. $Y$ value obtained from the temperature value read, for the value of $\mathrm{X}$ obtained from multiples of 15 seconds so that the data will form the pattern coordinates $(\mathrm{X} 1, \mathrm{Y}) ;(\mathrm{X} 2, \mathrm{Y}) ;(\mathrm{X} 3, \mathrm{Y}) ;(\mathrm{X} 4, \mathrm{Y})$;

4) Output measurement circuit Band Pass Filter On Oscilloscope

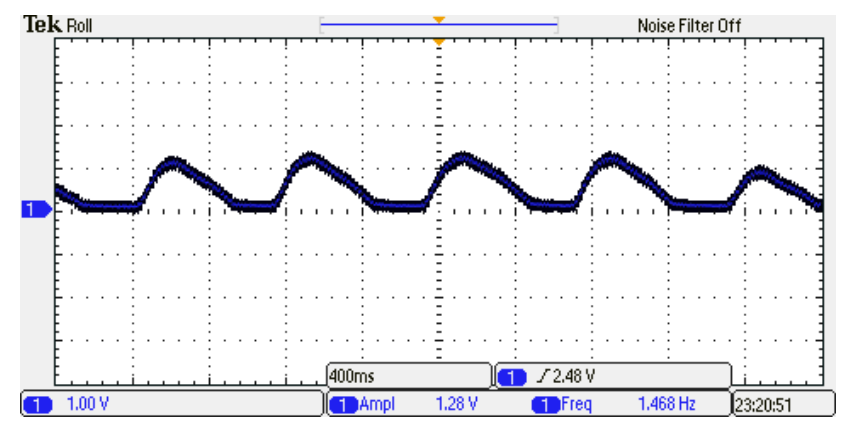

Fig. 16. Output TP3 Band Pass Filter

Fig. 15 is the result of the measurement on the output of the circuit TP3 Band Pass Filter. The output of the circuit TP3 Band Pass Filter is a signal that has passed through a series of Low Pass Filter with a cut off frequency of $2.34 \mathrm{~Hz}$ and strengthened by 101 times. BPM signal has been read frequency of $1.46 \mathrm{~Hz}$.
5) The Error of BPM (Beats Per Minutes) value

The measurement results of BPM to 5 respondents compared with Pulse Oximetry. The error value shown in Table I.

TABLE I. THE ERROR OF MEASUREMENT FOR BPM PARAMETER BETWEEN STANDARD UNIT (PULSE OXIMETRY).

\begin{tabular}{|c|c|}
\hline Respondent & Error (\%) \\
\hline 1 & 0.2506 \\
\hline 2 & 0.7444 \\
\hline 3 & 0.2681 \\
\hline 4 & 0.5263 \\
\hline 5 & 0.5249 \\
\hline $\begin{array}{c}\text { Average } \\
\text { Error }\end{array}$ & 0.4629 \\
\hline
\end{tabular}

Based on the results of measurements using Pulse Oximeter as a means of comparison obtained different results/ there is a difference in value. Values obtained the greatest error is $0.7444 \%$ and the least of which is $0.2506 \%$. The average error value of the measurement is $0.4629 \%$.

\section{6) The Error of Body Temperature value}

Results of measurement of body temperature to 5 respondents compared with Digital Thermometer. The error value is shown in Table II.

TABLE II. THE ERROR OF MEASUREMENT FOR BODY TEMPERATURE PARAMETER BETWEEN STANDARD UNIT (THERMOMETER DIGITAL)

\begin{tabular}{|c|c|}
\hline Respondent & Error (\%) \\
\hline 1 & 0.39 \\
\hline 2 & 0 \\
\hline 3 & 0.507 \\
\hline 4 & 0.285 \\
\hline 5 & 0.408 \\
\hline $\begin{array}{c}\text { Average } \\
\text { Error }\end{array}$ & 0.318 \\
\hline
\end{tabular}

Based on the results of measurements using a digital thermometer as a means of comparison obtained different results / there is a difference in value. Values obtained the greatest error is $0.507 \%$ and the smallest is $0 \%$. The average error value of the measurement is $0318 \%$.

\section{DISCUSSION}

Based on the measurement signal in the circuit of the Band Pass Filter, the output at test point 3, which has been given the 
strengthening of the non-inverting amounted to $101 \mathrm{x}$ the output amplitude value of $1.28 \mathrm{~V}$. the Measurement of the BPM and the body temperature is performed directly on the human body and compared with the tool pulse oxymetry to detect the BPM and a digital thermometer to detect the temperature. The average value of the error obtained from the measurement of BPM between modules with pulse oxymetry that is $0.46 \%$ and the average error obtained from the measurement of the temperature between the modules with a digital thermometer that is of 0.31 degrees Celsius.

\section{Conclusion}

Based on the results of the discussion and the purpose of making the module can be concluded that the module can display the value of the three parameters that have been processed by the Arduino program in which the results are displayed on the LCD $2 \times 16$ and the android application. Android applications that have been made can also work well for displaying the data that has been received from the microcontroller via Bluetooth. When measurements were taken in a series of Band Pass Filter with a cut off frequency of 0.5 $\mathrm{Hz}-2.34 \mathrm{~Hz}$ showed that the filter circuit BPF has proven to work well in accordance with the characteristics of the filter BPF that when the input frequency is below $0.5 \mathrm{~Hz}$ or above $2.34 \mathrm{~Hz}$ amplitude will be suppressed

\section{REFERENCES}

[1] H. Wahyu Artha Bayu Murthi, "Rancang Bangun Alat Ukur Detak Jantung Dan Suhu Tubuh Manusia Berbasis Mikrokontroler Atmega16," vol. 20, no. 1, pp. 18-24, 2014.

[2] B. B. Tan Suryani Sollu, Alamsyah, Muhammad Bachtiar, Ardi Amir, "Sistem Monitoring Detak Jantung dan Suhu Tubuh Menggunakan Arduino," vol. 17, no. 3, pp. 323-332, 2018.

[3] E. Riyanto, "Perancangan Pengukur Detak Jantung Dan Suhu Tubuh Berbasis Arduino Serta Smartphone Android," 2016.

[4] M. A. Saputro, E. R. Widasari, and H. Fitriyah, "Implementasi Sistem Monitoring Detak Jantung dan Suhu Tubuh Manusia Secara Wireless," vol. 1, no. 2, 2017.

[5] R. A. Rano K. Sinuray , Dika P. Destiani, "Cost of Illness dan Cost Containment Analysis Penggunaan Antibiotik Empirik Kombinasi pada Pasien Sepsis di Bandung," vol. 1, pp. 127-135, 2012.

[6] T. Brown, A. Ghelani-Allen, D. Yeung, and H. B. Nguyen, "Comparative effectiveness of physician diagnosis and guideline definitions in identifying sepsis patients in the emergency department," J. Crit. Care, vol. 30, no. 1, pp. 71-77, 2015.

[7] Y. Alif, K. Utama, and S. St, "Perbandingan Kualitas Antar Sensor Suhu dengan Menggunakan Arduino Pro Mini," vol. 2, no. 2, 2016.

[8] S. V. VIRAKTAMATH, N. Vernekar, N. Patil, and P. Angadi, "Heart Beat and Temperature Monitoring Using Zigbee Protocol," Int. J. Adv. Electron. Comput. Sci., vol. 2, no. 12, pp. 111-114, 2015.

[9] B. Mallick and A. K. Patro, "International Journal of Science, Engineering and Technology Research (IJSETR)," Hear. Rate Monit. Syst. Using Finger Tip Through Arduino Process. Softw., vol. 5, no. 1, pp. 84-89, 2016.

[10] V. R. Parihar, A. Y. Tonge, and P. D. Ganorkar, "Heartbeat and temperature monitoring system for remote patients using arduino," Int. J. Adavance Eng. Res. Sci., vol. 6495, no. 5, pp. 55-58, 2017. 